\title{
BUBUR SIMBUT SEBAGAI PERINTANG WARNA DALAM PEMBUATAN RAGAM HIAS PADA KAIN
}

\author{
Bayu Wirawan D. S., Inva Sariyati, Yustiana Dwirainaningsih \\ Politeknik Pusmanu Program Studi Teknik Batik \\ J1. Jenderal Sudirman 29 Pekalongan \\ bayuwirawands@politeknikpusmanu.ac.id
}

\begin{abstract}
Simbut porridge as a color barrier in making decorative items on fabrics and can be used by all people, even children. During this time in the introduction of batik to children using candles or hot nights. This has a high risk because children are still unstable and like to joke, so it is feared that the hot night will hurt them. With the use of simbut slurry the risk can be minimized because the simbut slurry is made from a safe and environmentally friendly material. Thus the introduction of batik to the younger generation can be carried out as early as possible. By using simbut porridge, it is expected to reduce the production costs of batik making. The raw material for the simbut pulp is easy to get, and relatively cheap. The process of making and using simple simbut slurry can be applied on an industrial scale and even on households. The application of simbut porridge can also be used as a means of introducing batik to all people from the ages of children to adults.
\end{abstract}

Keywords: Simbut porridge, Color barrier, Ornamental variety

\begin{abstract}
ABSTRAK
Bubur simbut sebagai perintang warna dalam pembuatan ragam hias pada kain serta dapat digunakan oleh semua kalangan, bahkan anak-anak. Selama ini dalam pengenalan batik pada anak-anak menggunakan lilin atau malam panas. Hal tersebut memiliki resiko tinggi karena anak-anak masih belum stabil dan suka bercanda, sehingga dikhawatirkan malam panas tersebut melukai mereka. Dengan penggunakaan bubur simbut resiko tersebut dapat diminimalisir karena bubur simbut terbuat dari bahan yang aman dan ramah lingkungan. Dengan demikian pengenalan batik pada generasi muda dapat dilaksanakan sedini mungkin. Dengan menggunakan bubur simbut, diharapkan dapat menekan biaya produksi pembuatan batik. Bahan baku bubur simbut mudah didapat, dan relatif murah. Proses pembuatan dan penggunaan bubur simbut yang sederhana dapat diaplikasikan dalam skala industri bahkan rumah tangga. Pengaplikasian bubur simbut juga dapat dijadikan sarana pengenalan batik bagi masyarakat semua kalangan mulai dari usia anak-anak hingga dewasa.
\end{abstract}

Kata Kunci : Bubur simbut, Perintang warna, Ragam hias

\section{PENDAHULUAN}

Bangsa Indonesia merupakan Negara kepulauan terbesar di dunia ini memiliki ratusan suku bangsa dengan kebudayaannya yang sangat beragam. Mulai dari adat istiadat, bahasa tradisional, kuliner, hingga kain tradisional. Kain batik yang sudah terkenal hingga keseluruh dunia karena keunikan yang dimilikinya. Bahkan pada tahun 2009, UNESCO menobatkan kain batik sebagai warisan kemanusiaan untuk budaya lisan dan non-bendawi. Selain batik, negara Indonesia juga memiliki kaintra disional lain yang tidak kalah unik dan indah. Salah satunya adalah kain simbut.

Sebelum ditemukan malam, konon di Banten, orang menggunakan bubur ketan hitam sebagai tinta untuk membuat motif pada kain mori. Mereka menamakannya batik simbut yang berarti selimut. Pada zaman Kerajaan Tarumanegara pada abad V, ada artefak kain simbut yang menggunakan bahan dari bubur ketan sebagai perintang. (AzyumardiAzra, 2008) 
Perkembangan peradaban manusia, dimanasaja, melalui berbagai tahap. Salah satunya adalah tahap membuat bahan pakaian. Di masa lampau bahan pakaian juga dibuat dari kulit kayu yang dipukul-pukul hingga pipih, lalu disambung menjadi lembaran. Kemudian orang mengenal teknik pintal dantenun, yang menghasilkan kain tenun benang. Perkembangan berikutnya adalah menghiasnya. Diwarnai, dihias dengan corak (motif, ragam hias) tertentu, dan sebagainya.(Iwan tirta, 2009)

Salah satu cara membubuhkan ragam hias pada permukaan kain adalah teknik menahan pewarna. Bahan untuk menahan pewarna itu harus mudah menempel di permukaan kain dan tidak tembus pewarna. Dalam lingkungan rumah tangga di kepulauan Nusantara, bahan yang cocok untuk itu adalah bubur beras ketan. Pada permukaaan kain yang terbentang rata, bubur yang masih hangat dioleskan dengan batang bambu yang dimemarkan, membentuk ragam hias tertentu. Setelah bubur kering, kain dioles dengan atau dicelup dalam cairan pewarna. Karena bubur tidak tembus cairan, maka bagian yang tertutup bubur tidak tembus pewarna. Ketika bubur sudah dilepas dari permukaan kain, muncullah ragam hias yang semula tertutup bubur. Inilah teknik penahan pewarna paling sederhana di Indonesia. (Iwan tirta, 2009)

Bubur beras ketan yang sudah kering mudah retak-retak. Alat untuk mengoleskannya ke kain pun masih sangat sederhana. Karena itu ragam hias kain-kain simbut juga sederhana saja, tidak rumit. Lazimnya bentuk-bentuk geometris yang besar. Garis-garis yang terbentuk pun tidak mulus, tetapi banyak retakan baik di tengah maupun sepanjang tepian garis. Bahan pewarna diambil dari alam, baik bagian-bagian tumbuhan (akar, kulit kayu, daun, bunga dan buah). Akan tetapi warna-warna yang dihasilkan boleh dianggap "mempesona" untuk masa kini. Biru pekat, merah dalam berbagai nuansa, cokelat dan lainlain.(Iwan tirta, 2009)

Bubur simbut sebagai bahan perintang warna dapat digunakan oleh semua kalangan, bahkan anak-anak. Selama ini dalam pengenalan batik pada anak-anak menggunakan lilin atau malam panas. Hal tersebut memiliki resiko tinggi karena anak-anak masih belum stabil dan suka bercanda, sehingga dikhawatirkan malam panas tersebut melukai mereka. Dengan penggunakaan bubur simbutresiko tersebut dapat diminimalisir karena bubur simbut terbuat dari bahan yang aman dan ramah lingkungan. Dengan demikian pengenalan batik pada generasi muda dapat dilaksanakan sedini mungkin.

Industri batik sekarang ini dihadapkan pada dilema dimana bahan baku dan biaya produksi batik yang tinggi sedangkan minat dan daya beli masyarakat terhadap batik kurang. Dengan menggunakan bubur simbut, diharapkan dapat menekan biaya produksi pembuatan batik. Bahan baku bubur simbut mudah didapat, dan relatif murah. Selain itu, pelepasan bubur simbut dari kain tidak memerlukan air panas cukup dengan air dingin saja. Ini berarti dapat menghemat biaya produksi.

\section{RUMUSAN MASALAH}

Potensi bubur simbut sebagai media pengenalan batik yang ramah untuk anak-anak tidak diimbangi dengan kualitas bubur yang mudah retak ketika kering, sehingga perintangan warna tidak sempurna. Tepung ketan memiliki kadar amilosa yang rendah sehingga kemampuan untuk membentuk gel kurang yang mengakibatkan bubur rapuh dan mudah retak atau hancur ketika kering. Penggunaan tepung ketan sebagai bahan baku utama dalam pembuatan simbut perlu ditambah dengan bahan-bahan pendukung lainnya untuk menghasilkan bubur simbut dapat merintang warna dengan maksimal. 
Hal ini melatarbelakagi penulis untuk membuat penelitian atau inovasi supaya bubur simbut tidak mudah retak dan dapat diaplikasikan dengan berbagai alat sehingga dapat menghasilkan ragam hias yang lebih halus dan rumit.

\section{TINJAUAN PUSTAKA}

\subsection{Kain Simbut}

Bukti bahwa seni batik telah dimiliki oleh bangsa Indonesia sejak dahulu adalah adanya kain batik Simbut dari Priangan. Kain batik ini merupakan contoh batik asli yang dibuat dari bahan kanji ketan sebagai penutup kain/perintang warna. Adapun kain simbut terbuat dari mori yang merupakan hasil pintalan dan tenunan sendiri penduduk setempat, dan tidak menggunakan malam (wax) sebagai perintang warna namun menggunakan kanji (jenang) beras ketan. Selain itu, kain tersebut memiliki hiasan sederhana dan lebih banyak menggunakan warna merah tua. ( $V$. KristantiPutriLaksmi, 2011)

\subsection{Teknik Rintang Warna}

Adapun perintangan adalah suatu teknik pembentukan motif dengan cara menutupi dan merintangi menggunakan material atau bahan yang bersifat resis terhadap zat warna yang digunakan untuk mencelup kain. Teknik seperti ini dalam bahasa Inggris dikenal dengan nama wax-resist dyeing. (Sa'du, 2010) .

Perkembangan perintang warna di Indonesia antara lain teknik ikat celup (jumputan, sasirangan, tritik, pelangi) dan batik. Sedangkan di negara lain ditemukan teknik lain yaitu di Nigeria (adireeleko) danJepang (katazome) yang keduanya menggunakan pasta berbahan dasar tepung tapioca dan tepung beras sebagai perintang warna pada kain. (HanifahFitriani, 2017).

\section{METODE PENELITIAN}

Untuk mendapatkan data - data yang dibutuhkan maka digunakan metode-metode sebagai berikut:

a) Pembuatan bubur simbut yang meliputi uji komposisi dan uji hasil pembuatan.

b) Studi Pustaka dan Studi Lapangan

\subsection{Alat dan Bahan Percobaan}

\subsubsection{Pembuatan Bubur Simbut}

Berdasarkan penemuan Philipboash bahan-bahan yang digunakan dalam pembuatan bubur simbut adalah sebagai berikut:
a) 150 gr tepung beras ketan
b) 200 gr gula jawa
c) 90 gr tawas
d) $650 \mathrm{cc}$ air bersih
e) 5 grBensoat
f) 80 gr lem PVAC

Rebus air sampai mendidih, kemudian masukan gula jawa dan tawas hingga larut. Setelah bahan larut masukan tepung beras ketan aduk sampai mengental, diamkan hingga dingin setelah itu masukan bensoat dan lem PVAC.

\subsubsection{Langkah-langkah Pembuatan Kain Simbut}

Langkah-langkah dalam membuatkain simbut adalah :

a) Siapkan kain, potong kain ke dalam ukuran yang diinginkan

b) Membuat sketsa 
c) Melekatkan bubur simbut pada kain

d) Biarkan hingga bubur simbut kering

e) Proses pewarnaan

f) Pelorodan dengan air dingin

g) Keringkan

\subsection{Langkah Percobaan}

Langkah percobaan merupakan tahapan-tahapan yang dilakukan dari persiapan bahan baku hingga menjadi sesuatu yang dapat diamati sesuai dengan hasil yang diinginkan. Pada tiap proses terdap tahapan - tahapan tersendiri. Untuk lebih jelas tentang langkah percobaan dari penelitian ini dapat dilihat pada gambar 1 berikut.

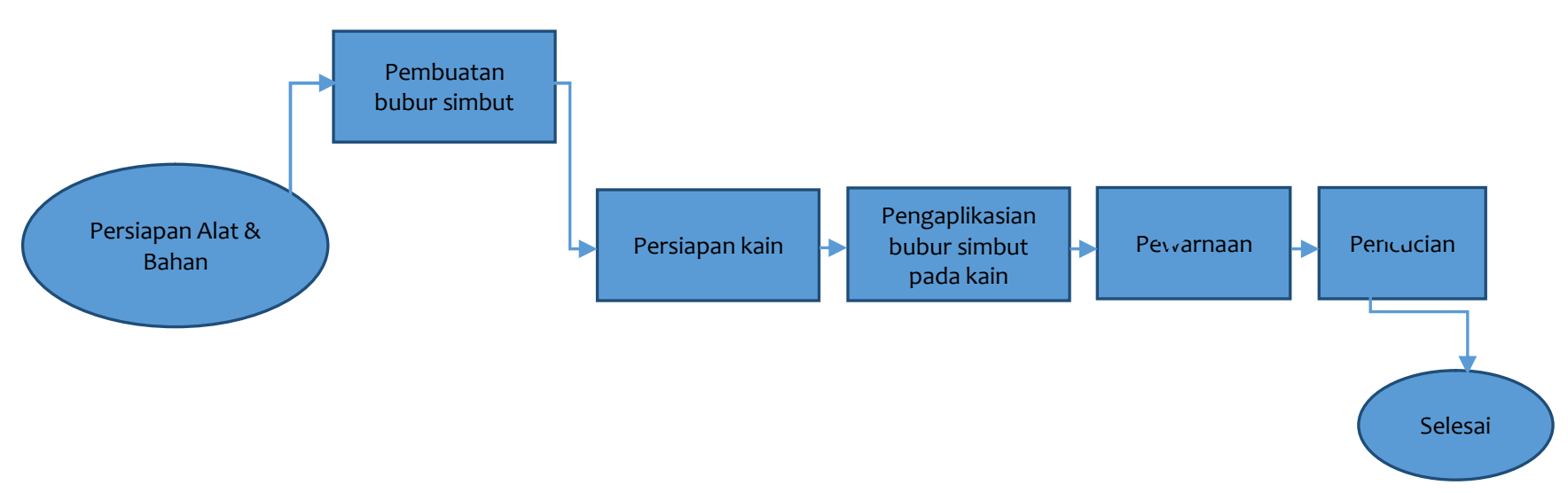

Gambar 1 Diagram Alur Proses Penelitian

\section{HASIL DAN PEMBAHASAN}

\subsection{Langkah Membuat Bubur Simbut}

a) Larutkan gula merah dan tawas dalam air mendidih, hingga air berkurang $30 \%$.

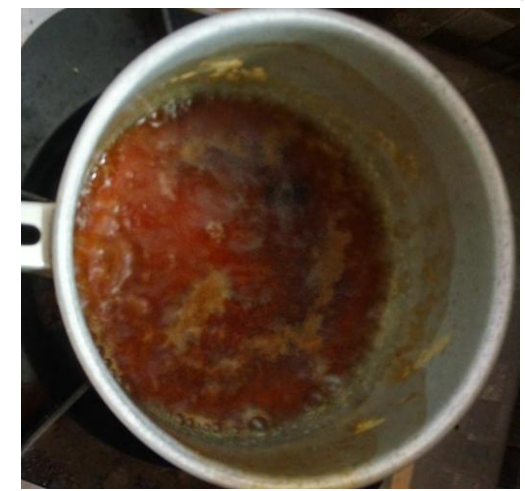

Gambar 2 Larutan Gula dan Tawas

b) Campurkan tepung ketan dengan air dingin, aduk perhalan sampai tidak ada gumpalan

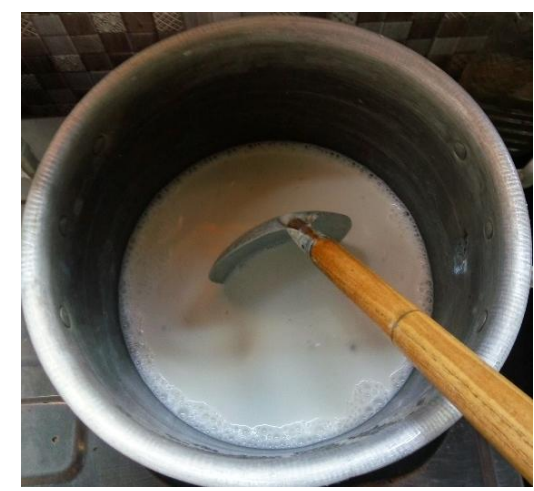

Gambar 3 Larutan Tepung Ketan 
c) Masukan larutan gula dan tawas ke dalam larutan tepung ketan, didihkan hingga bubur mengental.

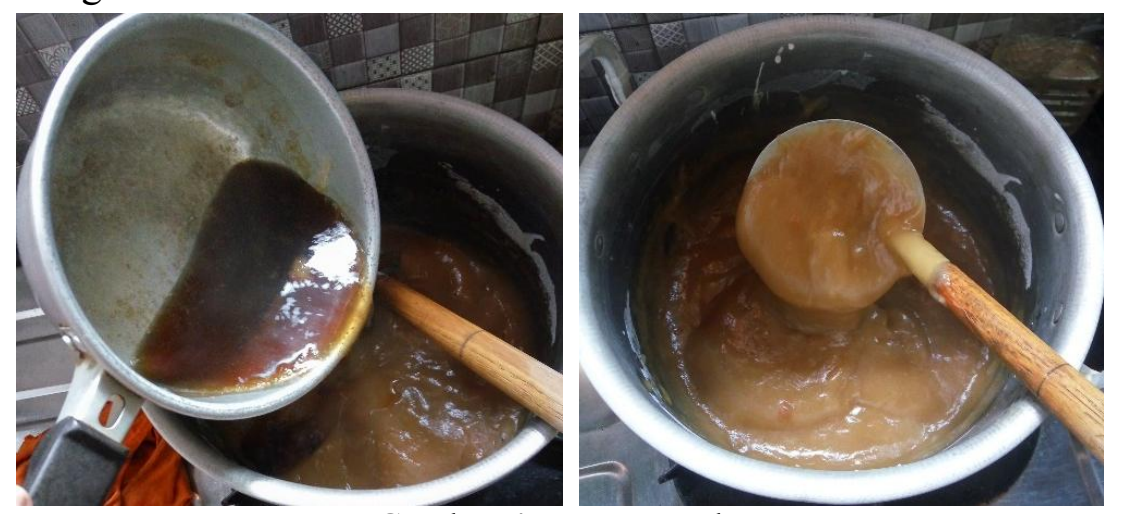

Gambar 4 Proses Perebusan

d) Setelah bubur dingin campurkan lem PVAC ke dalam bubur. Untuk mendapatkan bubur yang tidak menggumpal gunakan alat bantu seperti mixer

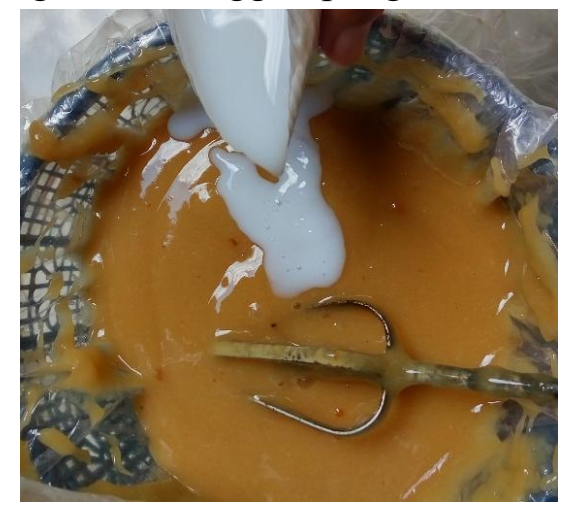

Gambar 5 Penambahan Lem PVAC

e) Setelah pembuatan bubur selesai, masukan bubur ke dalam botol.

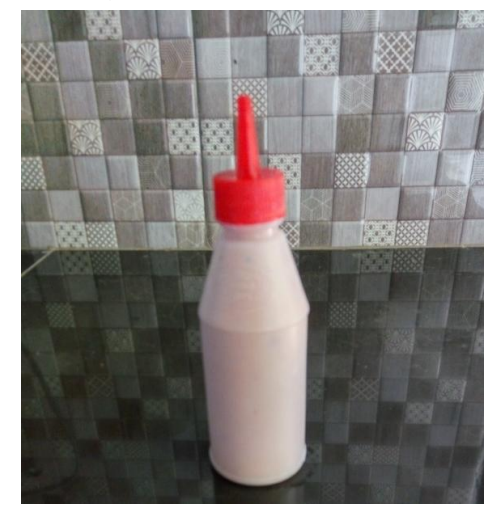

Gambar 6 Bubur Simbut dalam Botol

\subsection{Langkah Membuat Kain Simbut}

a) Langkah 1: Menyiapkan Kain

Cuci kain dengan tangan dan gunakan deterjen lalu bilas. Setelah itu, angkat dan keringkan.

b) Langkah 2: Membuat Desain

Buat sketsa desain pada selembar kertas, pertama dengan pensil lalu tebalkan dengan spidol hitam, ini akan menjadi pola desain.Kemudian buat desain dengan rasio 1: 1 pada kertas roti.

c) Langkah 3: Persiapan bingkai 
Bingkai kayu digunakan untuk menyebarkan kain agar bias ditarik. Bingkai bias terbuat dari kayu atau bahan lainnya, bahkan bias menggunakan bingkai foto yang tidak terpakai. Kayu harus cukup lunak agar pin mudah dipasang kekayu. Bingkai yang akan digunakan harus dilapisi dengan lakban atau cat kayu sehingga warnanya tidak menempel pada kayu. Hal ini akan mengakibatkan cat tembus / menempel pada kayu dan sulit dibersihkan, sehingga akan mencemari kain yang akan dibentangkan.

d) Langkah 4: Penjaplakan desain

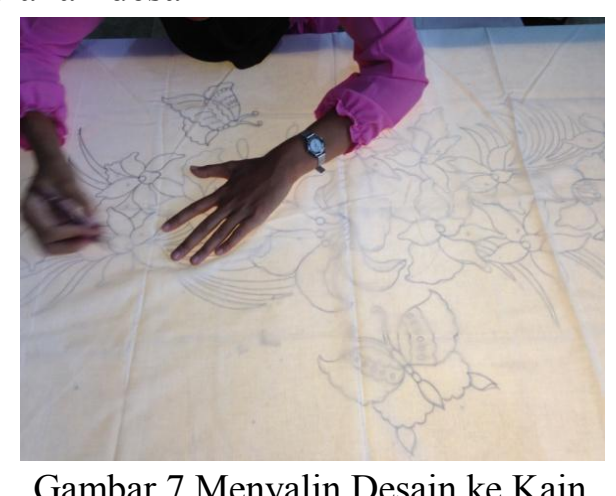

Desain yang telah dibuat pada kertas roti harus dipindahkan dengan menggambar ulang dengan referensi atau menyalin gambar. Letakkan kain di atas pola desain, dengan menggunakan pensil, pindahkan desain kekain dengan menelusuri jejak garis desain.

e) Langkah 5: Memasangkain

Peregangan dan peregangan kain diatas bingkai kayu, jadi terentang kencang, diperkuat dengan semacam pin khusus untuk kain.

f) Langkah 6: Pengaplikasian Simbut

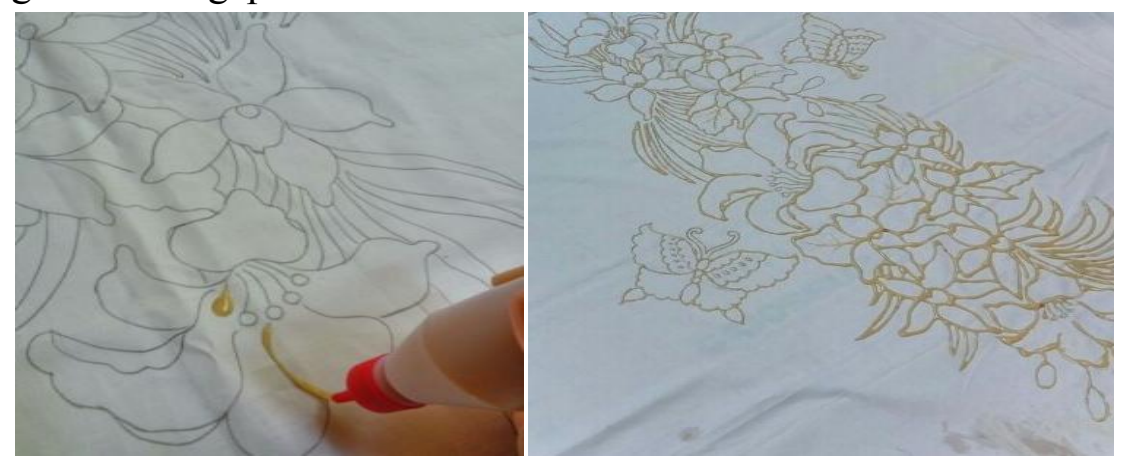

Gambar 8 Pengaplikasian Simbut

Pegang botol aplikator yang berisi bubur simbut secara vertical dengan ujung menyentuh kain, tarik garis dengan lembut dan perlahan saat menggam bargaris pada pola yang sudah tersedia. Biarkan kering.

g) Langkah 7: Pewarnaan
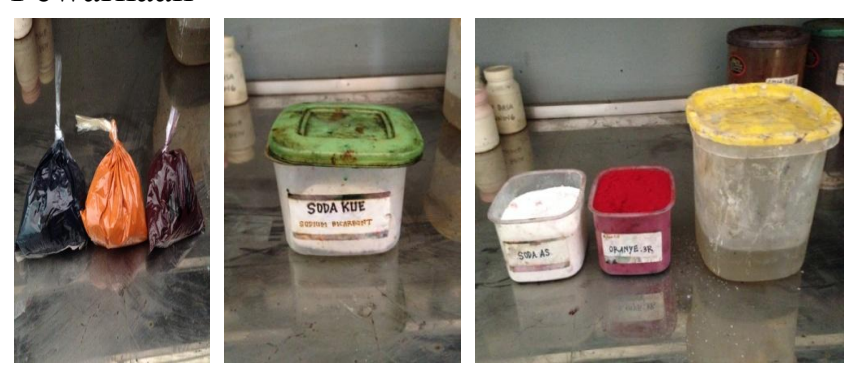

Gambar 9 Zat Warna 
Sebelum mengaplikasikan warna pada kain, pertama baurkan warna sesuai kebutuhan.

Setelah pewarna diolah, sebaiknya di coba dulu pada jenis kain yang sama, apakah warnanya sesuai dengan warna yang diinginkan .Gunakan kuas lembut untuk menyapu pewarna ke area tengah yang dikelilingisimbut.

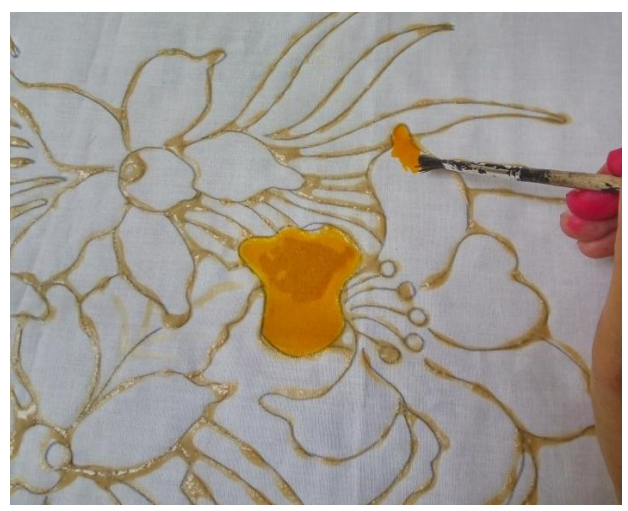

Gambar 10 Proses Pewarnaan

h) Langkah 8: Pelorodan dan Pencucian

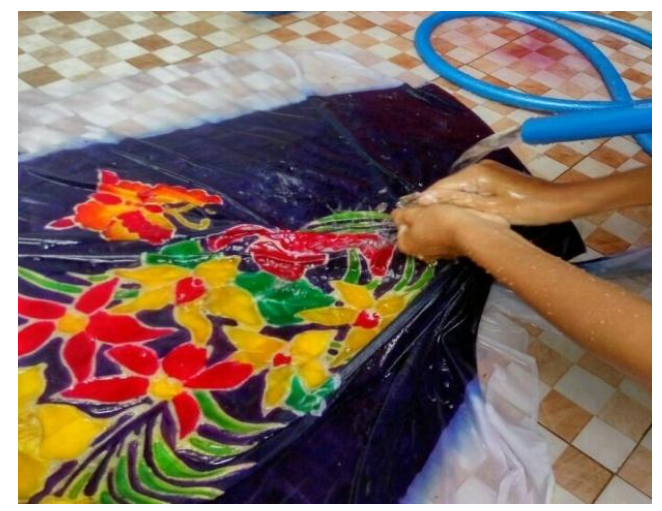

Gambar 11 Pelorodan dan Pencucian

Jika Anda telah selesai mengoleskan pewarna kekain, maka langkah selanjutnya adalah menghilangkan bubursimbut pada kain (pelorodan) dengan cara mencucinya dengan air dingin. Setelah itu jemur kain hingga kering.

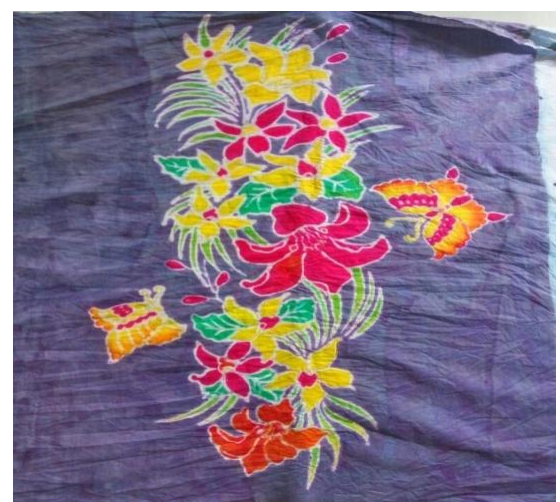

Gambar 12 Hasil Kain dengan Perintang Simbut 


\section{KESIMPULAN}

a) Keunikan dari bubur simbut dapat digunakan untuk menghasilkan produk yang inovatif. Penggunaan bubur simbut sebagai bahan perintang warna dapat diterapkan pengrajinpengrajin batik di Pekalongan karena bahan baku yang mudah didapat dimana saja.

b) Proses pembuatan dan penggunaan bubur simbut yang sederhana dapat diaplikasikan dalam skala industri bahkan rumah tangga.

c) Pengaplikasian bubur simbut juga dapat dijadikan sarana pengenalan batik bagi masyarakat semua kalangan mulai dari usia dewasa hingga anak-anak.

d) Penggunaan bubur simbut sebagai perintang warna memiliki potensi yang sangat tinggi. Simbut diharapkan dapat digunakan oleh masyarakat sebagai pengganti malam yang tidak berbahaya dan ramah lingkungan, terutama untuk pembelajaran bagi anak-anak usia dini.

e) Bagi industri, prospek pengembangan yang diharapkan dapat diproduksi secara masal sebagai alternatif pengganti malam dengan menggunakan alat yang lebih modern.

\section{DAFTAR PUSTAKA}

Ari wulandari, Batik Nusantara , makna filosofi, cara pembuatan dan industri batik, Andi Yogakarta, 2011

Anindito Prasetyo, Batik, Karya Agung Warisan Budaya Dunia, Pura Pustaka, Yogyakarta, 2010

Abdul Aziz Sa'du, Buku Panduan mengenal dan membuat Batik, Harmoni Yogyakarta, 2010

AzyumardiAzra, dkk., Reinventing Indonesia:MenemukanKembali Masa DepanBangsa, Mizan, Bandung, 2008

HanifahFitriani, Pengolahan Kulit Umbi Singkong (Manihotutilissima) di Kawasan Kampung Adat Cireundu sebagai bahan baku alternative Perintang Warna Pada Kain, e-Proceeding of Art \& Design : Vol.4, No.3 Desember 2017

Iwan Tirta , Batik Sebuah Lakon, Gaya Favorit Press, Jakarta, 2009

TitySoegiarty, Batik with Gutta Using Resist Techniques, Proceeding Of 2nd International Conference Of Arts Languange And Culture, The Improvement Of Socio-Cultural Community Life Through Contextual Art Education, Surakarta, 2017

V. Kristanti Putri Laksmi, Pembinaan Seni Batik Tulis Bagi Siswa SMA Negeri 2 Sukoharjo, Abdi Seni Jurnal Pengabdian Kepada Masyarakat, Volume 3 No. 1 Juni 2011 